\title{
Effect of increasing amounts of olive crude phenolic concentrate in the diet of dairy ewes on rumen liquor and milk fatty acid composition
}

\author{
Alice Cappucci, ${ }^{\star 1}$ Susana P. Alves, $†$ Rui J. B. Bessa, $†$ Arianna Buccioni, $\ddagger$ Federica Mannelli, $\ddagger$ \\ Mariano Pauselli,§ Carlo Viti,‡ Roberta Pastorelli,\# Valentina Roscini,§ Andrea Serra, ${ }^{*}$ Giuseppe Conte, ${ }^{*}$ \\ and Marcello Mele* \\ *Dipartimento di Scienze Agrarie, Alimentari e Agro-ambientali, University of Pisa, Via del Borghetto, 80, 56124 Pisa, Italy \\ †CIISA, Centro de Investigação Interdisciplinar em Sanidade Animal, Faculdade de Medicina Veterinária, Universidade de Lisboa, \\ Avenida da Universidade Técnica 1300-477, Lisboa, Portugal \\ ‡Dipartimento di Scienze delle Produzioni Agro-alimentari e dell'Ambiente, University of Florence, Piazzale delle Cascine 18, 50144 Firenze, Italy \\ §Dipartimento di Scienze Agrarie, Alimentari ed Ambientali, University of Perugia, Borgo XX Giugno 74, 06121 Perugia, Italy \\ \#Centro di Ricerca Agricoltura e Ambiente, Consiglio per la Ricerca in Agricoltura e l'Analisi dell'Economia Agraria, via di Lanciola 12/A, \\ 50125 Firenze, Italy
}

\section{ABSTRACT}

Agro-industrial by-products contain several secondary plant metabolites, such as polyphenols, tannins, saponins, and essential oils. The effects of these compounds on animal metabolism may vary significantly according to the dose, the chemical nature of the molecules, and the overall composition of the diet. In the Mediterranean area, the olive oil extraction is associated with 2 by-products: olive pomace and wastewater, both rich in polyphenols. In particular, wastewater may be further processed to obtain olive crude phenolic concentrate (OCPC). An experiment was carried out aiming to evaluate animal performance, milk fatty acid (FA) profile, diversity of rumen microbial population, and rumen liquor FA profile in dairy ewes fed diets containing extruded linseed (EL) and increasing doses of OCPC. Twenty-eight Comisana ewes in mid lactation were allotted to 4 experimental groups. The experiment lasted $5 \mathrm{wk}$ after $3 \mathrm{wk}$ of adaptation. Diets were characterized by lucerne hay administrated ad libitum and by $800 \mathrm{~g} /$ ewe and day of 4 experimental concentrates containing $22 \%$ of EL on dry matter and increasing dose of OCPC: 0 (L0), 0.6 (L0.6), 0.8 (L0.8), and $1.2(\mathrm{~L} 1.2) \mathrm{g}$ of $\mathrm{OCPC} / \mathrm{kg}$ of dry matter. Milk yield was daily recorded and milk composition was analyzed weekly. At the beginning and at the end of the experiment, samples of rumen liquor were collected to analyze FA profile, changes in rumen microbial population, and dimethylacetal (DMA) composition. The inclusion of OCPC did not affect milk yield and gross composition, whereas milk from L0.8 and L1.2 sheep

Received August 29, 2017.

Accepted January 29, 2018

${ }^{1}$ Corresponding author: alice.cappucci@for.unipi.it contained higher concentrations of linoleic $(+18 \%)$ and $\alpha$-linolenic acid $(+24 \%)$ and lower concentration of the rumen biohydrogenation intermediates. A similar pattern was observed for rumen liquor FA composition. No differences were found in the diversity of the rumen microbial population. Total amount of DMA did not differ among treatments, whereas significant differences were found in the concentration of individual DMA; in the diet with a higher amount of OCPC, DMA 13:0, 14:0, 15:0, and 18:0 increased, whereas DMA 16:0 decreased. Probably the presence of polyphenols in the diet induced a rearrangement of bacteria membrane phospholipids as a response to the rumen environment stimulus. Overall, the use of OCPC allowed a significant increase in the polyunsaturated FA content of milk, probably due to a perturbation of the rumen biohydrogenation process. Further studies are needed to understand the correlation between diet composition and the pattern of DMA in rumen liquor.

Key words: biohydrogenation, milk fatty acid, dimethylacetal, olive polyphenol

\section{INTRODUCTION}

The use of extruded linseed (EL) in the diet of dairy ruminants has been extensively studied as a feeding strategy to modify milk fatty acid (FA) composition (Chilliard et al., 2007; Mele et al., 2011). The addition of EL in the ruminant diet leads to an enrichment of milk and cheese with bioactive FA, such as PUFAn-3, CLA, and vaccenic acid (VA; Mele et al., 2011; Pintus et al., 2013). However, more than $85 \%$ of PUFA contained in EL are usually biohydrogenated (Buccioni et al., 2015b). As consequence, high amounts of dietary EL are needed to obtain milk with a FA profile rich in PUFA suitable for the production of cheese with a proven positive effect on human health (Mele et al., 
2011; Pintus et al., 2013), causing an increase in feeding costs.

Recent studies showed that feeding polyphenolic compounds to ruminants resulted in a perturbation of PUFA rumen biohydrogenation $(\mathbf{R B H})$ with no detrimental effects on milk yield and quality (Ferlay et al., 2010; Buccioni et al., 2015a). Moreover, in vitro studies suggested interference between dietary polyphenols and rumen microbiome profile (Pallara et al., 2014; Costa et al., 2017).

Several agro-industrial by-products contain considerable amounts of plant secondary metabolites, including different kind of polyphenols or other compounds such as saponins and essential oils, able to modulate RBH and, consequently, FA composition of ruminant-derived products (Vasta et al., 2008).

Olive oil extraction results in 2 main by-products: olive pomace and wastewater. More than $98 \%$ of total olive polyphenols accumulate in the wastewater during the oil extraction process. Olive polyphenols may be separated from the rest of the wastewater by applying an enzymatic treatment with depolymerizing enzymes, followed by a separation with membrane filters $(0.2 \mu \mathrm{m})$ as described in Servili et al. (2011). After this treatment, an olive crude phenolic concentrate (OCPC) is obtained, with a polyphenol content 4 times higher than that of the wastewater.

Olive crude phenolic concentrate is mainly composed of oleuropein-aglycone di-aldehyde (3,4-DHPEAEDA) and verbascoside, whereas hydroxytyrosol (3,4-DHPEA) and tyrosol (p-HPEA) are usually present at lower amounts (Servili et al., 2011).

A previous in vitro study suggested that polyphenols from olive pomace were probably able to interfere with RBH of dietary PUFA (Pallara et al., 2014). However, in dairy ewes, the effect of pure olive polyphenols on milk yield and composition is only scarcely studied (Casamassima et al., 2014). To investigate the response of microbes to changes in the rumen environment as affected by specific diet ingredients, recently dimethylacetal (DMA) analysis of the rumen liquor has been proposed (Alves et al., 2013). Dimethylacetals derive from plasmalogen lipids and seems to play an important role in the membrane fluidity of gram-negative bacteria. In particular, DMA profile has been proposed as potential marker of the response of rumen bacteria to the environmental condition (Katz and Keeney, 1964; Minato et al., 1988; Goldfine, 2010).

Thus, the effect of the inclusion of increasing amounts of OCPC, in combination with EL as a source of PUFA, in the diet of dairy ewes on milk traits and FA composition and on DMA and FA composition of rumen liquor was evaluated. Moreover, the effect of OCPC on overall rumen microbial community diversity was also investigated.

\section{MATERIALS AND METHODS}

\section{Experimental Design}

Twenty-eight pluriparous Comisana ewes in mid to late lactation $(107 \pm 9 \mathrm{~d})$ and homogeneous for BW $(68 \pm 2.5 \mathrm{~kg})$, kept at the Experimental Section of the Department of Agriculture, Food and Environmental Science, University of Perugia (Italy), were randomly allotted into 4 groups and confined in multiple pens (7 animals per pen).

The experimental trial lasted 5 wk after 3 wk of adaptation to the dietary regimen adopted for the present study. In the experimental period, the animals received 4 different diets based on chopped lucerne hay administrated ad libitum (particle size $>4 \mathrm{~cm}$ of length), $100 \mathrm{~g}$ of rolled barley, and $800 \mathrm{~g} /$ animal and day of a concentrate containing EL as source of PUFA, plus different amounts of OCPC to obtain different concentration of total polyphenols: 0 (L0), 0.6 (L0.6), 0.8 (L0.8), or $1.2(\mathbf{L} 1.2) \mathrm{g} / \mathrm{kg}$ of DM. The OCPC was obtained from the filtration of fresh vegetation wastewater, according to the procedure described by Servili et al. (2011). All the concentrate ingredients were incorporated into pellets using a pelleting machine (CMS-IEM, Colognola ai Coli, Verona, Italy). Pellet diameter was $5 \mathrm{~mm}$ and the pelleting temperature ranged between 35 and $40^{\circ} \mathrm{C}$. Ingredients and chemical composition of the experimental diets were reported in Table 1.

Diets were formulated according to the nutritional requirements of a dairy ewe weighing $68 \mathrm{~kg}$ and producing $1 \mathrm{~kg}$ of milk at $6.5 \%$ fat (Cannas et al., 2004). Four hundred grams of experimental concentrates and $50 \mathrm{~g}$ of rolled barley were individually fed during each milking until their consumption was completed.

The ewes were milked twice daily (0730 and 1730 h) using a milking machine (43 $\mathrm{kPa} ; 150$ pulsations/ min) and daily milk yield was individually recorded. The handling of the animals was in accordance with the Institutional Animal Care and Use Committee of the University of Perugia.

\section{Sampling and Analysis}

Feed Sampling and Analysis. Feed and orts samples were collected weekly, dried at $40^{\circ} \mathrm{C}$, ground using a Cyclotec 1093 mill (PBI International, Milan, Italy) with a mesh size of $1 \mathrm{~mm}$, and then stored at $-80^{\circ} \mathrm{C}$ until analysis. 
Table 1. Ingredients, chemical composition, and fatty acid profile of the lucerne hay, flaked barley, and experimental concentrates administrated to ewes

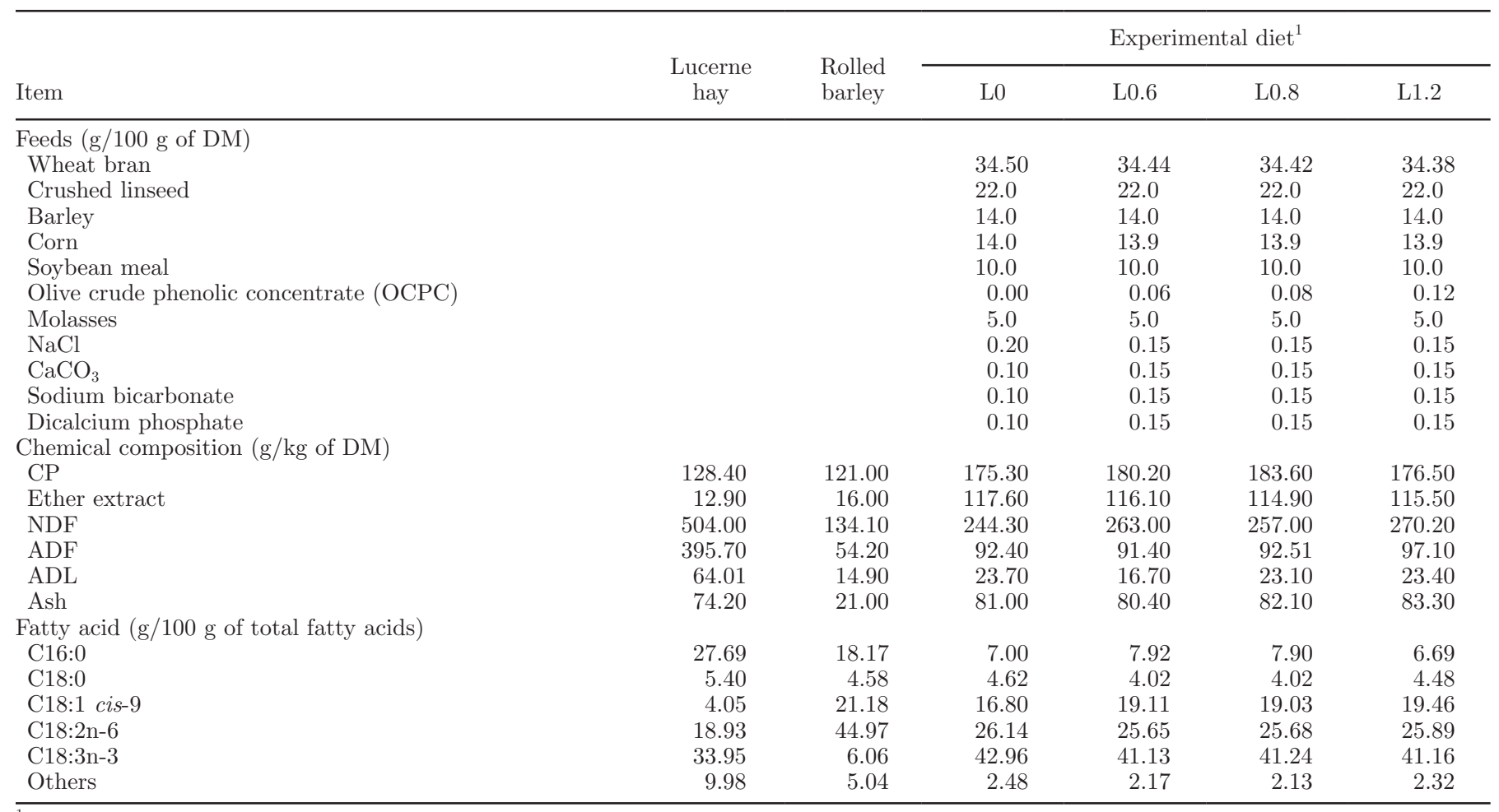

${ }^{1} \mathrm{~L} 0=$ control diet; $\mathrm{L} 0.6=$ control diet plus $0.6 \mathrm{~g} / \mathrm{kg}$ of OCPC; L0.8 = control diet plus $0.8 \mathrm{~g} / \mathrm{kg}$ of OCPC; L1.2= control diet plus $1.2 \mathrm{~g} / \mathrm{kg}$ of OCPC.

The content of $\mathrm{CP}$ and ether extract were determined according to the AOAC methods (976.06 and 920.39, respectively; AOAC International, 1995). The content of NDF, ADF, and ADL were determined using heatstable amylase and sodium sulfite, in according to Van Soest et al. (1991). The results were expressed inclusive of residual ash.

Lipids of feed samples were extracted according to Folch et al. (1957) and then FAME were obtained according to Christie (1982), using 19:0 (Sigma Chemical Co., St. Louis, MO) as the internal standard. Gas chromatography procedure and methods applied to identify and quantify feed FA were the same below described for milk FA analysis.

Phenolic compounds in the experimental concentrates were determined according to Servili et al. (2011) and reported in Table 2.

Milk Sampling and Analysis. Individual milk samples were collected weekly during the morning and evening milking. Milk samples were gathered in a single sample according to the morning and afternoon yield and, subsequently, split into 2 aliquots for analysis: the first aliquot was processed to evaluate fat, lactose, protein, and urea contents by using Milkoscan 6000 FT

Table 2. Phenolic compounds content in the experimental concentrates administrated to ewes

\begin{tabular}{|c|c|c|c|c|}
\hline \multirow[b]{2}{*}{ Item $(\mathrm{mg} / \mathrm{kg}$ of DM) } & \multicolumn{4}{|c|}{ Experimental concentrate $^{1}$} \\
\hline & L0 & L0.6 & L0.8 & $\mathrm{L} 1.2$ \\
\hline $3,4-$ DHPEA $^{2}$ & - & 107.87 & 111.50 & 146.32 \\
\hline p-HPEA ${ }^{2}$ & - & 52.07 & 69.64 & 103.74 \\
\hline Verbascoside & - & 248.18 & 354.87 & 530.07 \\
\hline 3,4 -DHPEA-EDA ${ }^{2}$ & - & 236.29 & 291.67 & 397.83 \\
\hline Total phenolic compounds & - & 644.41 & 827.68 & $1,177.96$ \\
\hline
\end{tabular}


(Foss Electric, Hillerød, Denmark) and SCC according to ISO 13366-2/IDF 148-2 (ISO-IDF, 2006), by using a Fossmatic 5000 (Foss Electric). Somatic cell count data were expresses as linear score (LS) where LS $=\log 2$ (SCC/12,500), according to Shook (1993).

The second aliquot of milk samples was analyzed for FA composition as follows: milk fat was extracted as reported in Mele et al. (2008). The FAME were prepared by alkali catalyzed trans-methylation procedure (Christie, 1982) with nonanoic (C9:0) and nonadecanoic (C19:0) acid methyl ester (Sigma Chemical Co.) as the internal standards.

The FA composition was determined using a GC2010 Shimadzu gas chromatograph (Shimadzu, Columbia, $\mathrm{MD}$ ) equipped with a flame-ionization detector and a high polar fused-silica capillary column (Chrompack CP-Sil 88 Varian, Middelburg, the Netherlands; 100 m, $0.25 \mathrm{~mm}$ i.d.; film thickness $0.20 \mu \mathrm{m})$. Hydrogen was used as the carrier gas at a flow of $1 \mathrm{~mL} / \mathrm{min}$. Split/ splitless injector was used with a split ratio of 1:80. An aliquot of the sample was injected under the following GC conditions: the oven temperature started at $60^{\circ} \mathrm{C}$ and held at that level for $1 \mathrm{~min}$; it was then increased to $173^{\circ} \mathrm{C}$ at a rate of $2^{\circ} \mathrm{C} / \mathrm{min}$, and held at that level for $30 \mathrm{~min}$, before being once again increased to $185^{\circ} \mathrm{C}$ at $1^{\circ} \mathrm{C} / \mathrm{min}$ and held for $5 \mathrm{~min}$, and then to $220^{\circ} \mathrm{C}$ at a rate of $3^{\circ} \mathrm{C} / \mathrm{min}$, and held for $19 \mathrm{~min}$. The injector temperature was set at $270^{\circ} \mathrm{C}$ and the detector temperature was set at $300^{\circ} \mathrm{C}$.

Individual FAME were identified and quantified according to Buccioni et al. (2015a). All FA composition results are expressed as grams per $100 \mathrm{~g}$ of FA.

Rumen Liquor Sampling and Analysis. Individual rumen liquor samples were collected from all animals involved in the experiment before the start of adaptation period to the experimental diets and at the end of the trial. The samples were collected by means of a stomach tube connected to an electrical pump before morning feeding, according to the procedure described by Buccioni et al. (2015a). The sampling was done from each animal after an overnight period without concentrate and hay distribution but with free access to water.

Immediately after collection, each sample was measured for $\mathrm{pH}$ and stored at $-80^{\circ} \mathrm{C}$ until analysis for $\mathrm{FA}$ and DMA composition. Before the analysis, samples were freeze-dried and then trans-esterified by using a combined basic and acid procedure, according to Jenkins (2010) as modified by Alves et al. (2013). Briefly, $250 \mathrm{mg}$ of freeze-dried rumen sample was put in a centrifuge tube and $1 \mathrm{~mL}$ of toluene and $1 \mathrm{~mL}$ of hexane containing internal standard $(\mathrm{C} 19: 0,1 \mathrm{mg} / \mathrm{mL})$ were added. The basic trans-esterification was performed by the addition of $2 \mathrm{~mL}$ of sodium methoxide in methanol $(0.5 \mathrm{M})$. The solution was vortexed and left to react for about $10 \mathrm{~min}$ at $50^{\circ} \mathrm{C}$. Subsequently, the mixture was cooled to room temperature and immediately added with $3 \mathrm{~mL}$ of $\mathrm{HCl}$ solution in methanol (10:90 vol:vol). The solution was allowed to react for $10 \mathrm{~min}$ at $80^{\circ} \mathrm{C}$. Once cooled, $2 \mathrm{~mL}$ of a solution $\mathrm{K}_{2} \mathrm{CO}_{3}$ (6:94 wt:vol) was added, followed by the addition of $2 \mathrm{~mL}$ of hexane to extract FAME and DMA. The solution was vortexed, centrifuged, and finally, the supernatant phase with FAME and DMA was transferred to another tube. The extraction step was repeated twice. Identification of DMA was performed by previous purification of DMA fraction by thin-layer chromatography, as described in Alves et al. (2013). The procedures for GC analysis and FAME identification were the same above described for the analysis of milk FAME. The identification of DMA was obtained by GC/MS, according to Alves et al. (2013).

DNA Extraction from Rumen Liquor. Genomic DNA was extracted from $1 \mathrm{~mL}$ of rumen microbial suspension using the Fast DNA SPIN kit for soil (Qbiogene, Carlsbad, CA). Each sample was homogenized with a FastPrep cell disrupter instrument (Bio101, ThermoSavant, Qbiogene) for $2 \times 40 \mathrm{~s}$ at speed 6.0 and then processed according to the manufacturer's guidelines. The DNA was eluted in sterile water and its integrity was verified by agarose gel electrophoresis. The amount and the purity of DNA was measured at 260 and $280 \mathrm{~nm}$ using a ND-1000 Spectrophotometer (NanoDrop Technologies, Labtech, Ringmer, UK).

PCR-Denaturing Gradient Gel Electrophoresis Analysis of the Total Bacterial Community. The analysis of total bacterial community was performed on a selected group of animals, according to the results obtained from FA composition of milk and rumen liquor samples. In particular, the analysis was performed on the DNA extracted from the rumen liquor of 5 animals of L0 and L1.2 groups. Moreover, DNA extracted from rumen liquor samples collected from the same animals at the sampling time before the beginning of the adaptation period was also considered in the analysis. This approach allowed evaluation of the distribution of bacterial communities before starting the experiment.

Total DNA extracted was diluted to a concentration of $5 \mathrm{ng} / \mu \mathrm{L}$ and $2 \mu \mathrm{L}$ of diluted DNA was used as template in PCR. Amplification of the V6-V8 region of the $16 \mathrm{~S}$ rRNA gene was carried out with the primer pair F968GC (5'-CGC CCG CCG CGC GCG GCG GGC GGG GCG GGG GCA CGG GGG GAA CGC GAA GAA CCT TAC-3') and R1401 (5'-CGG TGT GTA CAA GAC CC-3') for total eubacterial PCR (fragment size $\sim 470 \mathrm{bp}$ ). Reactions were carried out using a T100 Thermal Cycler (Bio-Rad Laboratories, Hertfordshire, UK) in $25-\mu \mathrm{L}$ volumes containing $1 \times$ 
Flexi PCR buffer (Promega, Madison, WI), $1.5 \mathrm{~m} M$ $\mathrm{MgCl}_{2}, 250 \mu M$ deoxynucleotide triphosphates, $400 \mathrm{n} M$ each primer, and $1 \mathrm{U}$ of GoTaq Flexi DNA polymerase (Promega). Amplifications were performed under the following conditions: an initial denaturation of $94^{\circ} \mathrm{C}$ for $5 \mathrm{~min}$ followed by 35 cycles of $94^{\circ} \mathrm{C}$ for $20 \mathrm{~s}, 56^{\circ} \mathrm{C}$ for $30 \mathrm{~s}$, and $72^{\circ} \mathrm{C}$ for $45 \mathrm{~s}$, and a final extension of $72^{\circ} \mathrm{C}$ for $10 \mathrm{~min}$. After PCR, amplified products were verified by agarose gel electrophoresis. Subsequently, to perform PCR denaturing gradient gel electrophoresis (DGGE) analysis, amplicons were loaded on a $6 \%$ polyacrylamide gel (40\% acrylamide/bis 37.5:1; Serva Electrophoresis GmbH, Heidelberg, Germany), with a 50 to $60 \%$ denaturing gradient $(100 \%$ denaturant consisting of $40 \% \mathrm{vol} / \mathrm{vol}$ deionized formamide, $7 \mathrm{M}$ urea) and electrophoresis was performed in a Dcode DGGE System (Bio-Rad Laboratories). The gels were run for $17 \mathrm{~h}$ at $60^{\circ} \mathrm{C}$ and $75 \mathrm{~V}$. After electrophoresis gels were stained with SYBR Gold (Molecular Probes, Eugene, OR) and images digitalized using ChemiDoc XRS (BioRad Laboratories).

The PCR-DGGE banding patterns obtained were normalized and analyzed using the software package GelCompar II Software v 4.6 (Applied Maths, SaintMartens-Latem, Belgium). To summarize the species number (richness) of rumen bacterial communities, each band was considered as corresponding to a single microbial species and the relative abundance of each band in DGGE profile (Shannon index) was used as a proxy of bacterial diversity (Pastorelli et al., 2011).

\section{Statistical Analysis of Data}

All variables (with the exception of rumen liquor FA and DMA, and rumen bacterial diversity indices) were processed as a completely randomized design with repeated measures using the following linear mixed model (SAS 9.2, 2013, SAS Institute Inc., Cary, NC).

$$
\mathrm{y}_{\mathrm{ijk}}=\mu+\mathrm{D}_{\mathrm{i}}+\mathrm{P}_{\mathrm{j}}+(\mathrm{D} \times \mathrm{P})_{\mathrm{ij}}+\mathrm{A}_{\mathrm{k}}\left[\mathrm{D}_{\mathrm{i}}\right]+\mathrm{e}_{\mathrm{ijk}},
$$

where $y_{i j k}$ is the observation, $\mu$ is the overall mean, $D_{i}$ is the fixed effect of diet ( $\mathrm{i}=1$ to 4$), \mathrm{P}_{\mathrm{j}}$ is the fixed effect of sampling time $(\mathrm{j}=1$ to 5$),(\mathrm{D} \times \mathrm{P})_{\mathrm{ij}}$ is the interaction between diet and sampling time, $\mathrm{A}_{\mathrm{k}}$ is the random effect of the animal nested within the diet $(\mathrm{k}=$ 1 to 5 ), and $\mathrm{e}_{\mathrm{ijk}}$ is the residual error.

The covariance structure was compound symmetry, which was selected based on Akaike's information criterion of the mixed model of SAS. Statistical significance of the diet effect was tested against variance of sheep nested within diet according to repeated measures design theory (Littell et al., 1998). Linear and quadratic coefficients of polynomial orthogonal contrasts for unequally spaced OCPC doses were determined using PROC IML of SAS and then these contrasts were used to test the linear and quadratic effects of OCPC inclusion.

With regard to FA and DMA composition of rumen liquor, data were analyzed by a different model because only one sample per animal at the end of experimental period was collected.

$$
\mathrm{y}_{\mathrm{k}}=\mu+\mathrm{b}_{1} \mathrm{X}_{1}+\left(\mathrm{b}_{2} \mathrm{X}_{1}\right)^{2}+\mathrm{e}_{\mathrm{k}}
$$

where $\mathrm{y}_{\mathrm{k}}$ was the dependent variable (individual FA expressed as $\mathrm{mg} / \mathrm{g}$ of $\mathrm{DM}), \mu$ was the overall mean, $\mathrm{X}_{1}$ was the independent variable (amount of OCPC supplemented: $0,0.6,0.8,1.2)$, $\mathrm{b}$ was the regression coefficient, and e was the residual error.

Linear and quadratic coefficients of polynomial orthogonal contrasts for unequally spaced OCPC doses were determined using PROC IML of SAS and then these contrasts were used to test the linear and quadratic effects of OCPC inclusion.

Data of rumen liquor DMA were also processed with a stepwise discriminant analysis (SAS 9.2) to individuate further variables able to discriminate diets. Only DMA that did not show significant differences in univariate analysis were considered. The selected variables were submitted to a canonical discriminant analysis to derive canonical functions that summarize the variation between groups. The efficiency in group identification was evaluated by the test of significance of Mahalanobis distance.

Data from PCR-DGGE analysis of DNA extracted from rumen liquor samples were used to obtain richness and Shannon diversity indexes (Pastorelli et al., 2011) that were analyzed by 1-way ANOVA followed by the Tukey's test for $P<0.05$. Data relative to the basal period were used as a covariate in the statistical model.

Band-matching data, exported as quantitative information, were standardized by calculating the relative intensity of each band (ratio of intensity of each band versus the total band intensity) and imported into PAST software (Hammer et al., 2001; http://folk.uio .no/ohammer/past) for multivariate statistical analysis.

One-way analysis of similarity (ANOSIM) and permutational ANOVA (PERMANOVA) were conducted to examine the statistical significance of the DGGE profiles. Nonmetric multidimensional scaling analysis was used to represent the distance between each bacterial community in a 2-dimensional space. All the analysis were conducted using the Bray-Curtis distance measure and 9,999 permutation tests. 


\section{RESULTS AND DISCUSSION}

\section{Animal Performance and Milk Composition}

The main phenolic compounds contained in the wastewaters are secoiridoids. They are represented by the dialdehydic form of decarboxymethyl elenolic acid linked to 3,4-DHPEA (3,4-DHPEA-EDA, oleuropein aglycone) or to p-HPEA (p-HPEA-EDA, ligstroside aglycone di-aldehyde), and by the monoaldehydic forms of the same molecules (3,4-DHPEA-EA and p-HPEAEA; Obied et al., 2008). These compounds originate during the extraction process of the olive oil, as aglycone derivatives of native secoiridoid glucosides (namely oleuropein, dimethyl oleuropein, and ligstroside) contained in the olive fruit. Additionally, verbascoside, a derivative of hydroxycinnamic acid, which contains the 3,4-DHPEA in its molecular structure, may be also present in the phenolic fraction of wastewaters from olive oil extraction (Servili et al., 1999). In the OCPC used to formulate the experimental concentrate we found 3,4-DHPEA, p-HPEA, 3,4-DHPEA-EDA, and verbascoside (Table 2). The presence of 3,4-DHPEA, pHPEA was mainly due to the hydrolysis of 3,4-DHPEAEDA and p-HPEA-EDA (Servili et al., 1999). Into the wastewater, all the above reported phenolic compounds are in a dynamic equilibrium and may shift between different forms very rapidly (Obied et al., 2008). Hence, we analyzed the concentrate containing increasing levels of OCPC to check the actual amounts of individual phenolic substances included in the experimental concentrates. As reported in Table 2, the total amount of polyphenols across experimental concentrates increased in accordance with the amounts of OCPC used to formulate the concentrates (Tables 1 and 2). On the other hand, the distribution of individual phenolic compounds was not fully consistent with the pattern of total polyphenols in the concentrates (Table 2), suggesting a lack of stability of the phenolic substances of OCPC during the production of the experimental concentrates (Servili et al., 2011).
During the experiment, the average DMI of experimental groups was $1.92 \pm 0.07,1.93 \pm 0.12,1.93 \pm$ $0.06,1.90 \pm 0.07 \mathrm{~kg} /$ animal and day for L0, L0.6, L0.8, and L1.2, respectively. As reported in Table 3, dietary treatments did not affect milk yield and milk composition (fat, protein, lactose, and urea). Because no data are available in literature about the use of OCPC in the diet of ruminants, comparisons may be only made with studies adopting raw materials rich in polyphenols such as olive pomace. Previous studies about the introduction of olive pomace in the diet of small ruminants are not consistent about the effect on milk yield and composition. Molina-Alcaide et al. (2010) observed no differences in milk yield including crude olive pomace in the diets of dairy goats, whereas Chiofalo et al. (2004) found an increase in productive performance of dairy ewes. However, these studies did not report the amount of phenols contained in the olive pomace neither the profile. Hence the inconsistence of results might be related to the total amount of polyphenols and to the ratio among single molecules present in the extract. The phenolic compounds contained in the olive by-products (pomace, wastewater) are in a dynamic equilibrium and may shift to different chemical forms very rapidly.

In the present study, the amount of verbascoside administrated to ewes did not significantly affect milk yield. This result did not agree with Casamassima et al. (2014) who reported a positive effect of microencapsulated verbascoside on milk yield and composition in dairy ewes at mid lactation fed with an antioxidant supplement titrated at $0.5 \%$ of verbascoside. In the trial of Casamassima et al. (2014), other components of the supplement probably contributed to enhance milk yield or preserve verbascoside by rumen degradation. In particular, microencapsulation may have preserved verbascoside from rumen degradation in the experiment of Casamassima et al. (2014). In fact, the fate of verbascoside in the rumen liquor is likely similar to that of other phenolic glycosides with similar molar weight,

Table 3. Milk yield and composition from ewes fed with lucerne hay and $800 \mathrm{~g} /$ ewe per day of experimental concentrates containing increasing doses of olive crude phenolic concentrate (OCPC)

\begin{tabular}{|c|c|c|c|c|c|c|c|}
\hline Item & \multicolumn{4}{|c|}{ Experimental diet ${ }^{1}$} & SEM & \multicolumn{2}{|c|}{$P$-value } \\
\hline Milk yield (g/d) & 705.3 & 611.1 & 617.1 & 672.4 & 84.2 & 0.546 & 0.465 \\
\hline Protein $(\mathrm{g} / 100 \mathrm{~g})$ & 6.31 & 6.14 & 6.11 & 6.22 & 0.32 & 0.787 & 0.987 \\
\hline Lactose (g/100 g) & 4.46 & 4.39 & 4.43 & 4.36 & 0.17 & 0.546 & 0.478 \\
\hline Urea $(\mathrm{mg} / \mathrm{dL})$ & 35.85 & 32.02 & 35.95 & 39.58 & 5.22 & 0.576 & 0.767 \\
\hline
\end{tabular}

${ }^{1} \mathrm{~L} 0=$ control diet; $\mathrm{L} 0.6=$ control diet plus $0.6 \mathrm{~g} / \mathrm{kg}$ of OCPC; $\mathrm{L} 0.8=$ control diet plus $0.8 \mathrm{~g} / \mathrm{kg}$ of OCPC; L1.2= control diet plus $1.2 \mathrm{~g} / \mathrm{kg}$ of OCPC. 
such as rutin, which are hydrolyzed in the rumen with subsequent cleavage of the heterocyclic ring (McSweeney et al., 2001).

Interestingly, milk urea content (that is directly related to hematic urea) did not vary among treatments, suggesting that olive phenols did not interact in the rumen with the dietary protein metabolism (Table 3), unlike other phenolic substances such as tannins (Frutos et al., 2004; Buccioni et al., 2015a). However, in the present study, the amount of polyphenols added to the diet was very low if compared with the dose adopted in the experiment based on tannin supplementation (Frutos et al., 2004; Buccioni et al., 2015a).

\section{Rumen Microbial Ecosystem}

Many species of bacteria, archaea, and eukaryotes present in the rumen are still unknown and only a few number of them are isolated and physiologically characterized (Kong et al., 2010).

The rumen liquor samples of ewes collected before starting the experimentation and fed with L0 and L1.2 experimental diets were analyzed with PCR-DGGE. This approach allowed comparison of the extreme treatments. The $16 \mathrm{~S}$ rRNA genes were amplified to have an overview of the diversity of total bacteria communities.

Richness and Shannon-Weiner index calculated on 16S rDNA DGGE profiles ranged from 10 to 23 and from 2.27 to 3.11 , respectively, and no significant differences were found between L0 and L1.2 samples.

The analysis of total bacteria PCR-DGGE profiles highlighted a significant difference between the treatments, probably due to the influence of the olive polyphenols. The nonmetric multidimensional scaling analysis of bacterial DGGE fingerprints (Figure 1) evidenced a clear separation between community before starting the experiment and at the end of the experiment. Moreover, the pattern of bacterial communities differed according to the experimental diets. This separation was confirmed by ANOSIM and PERMANOVA analysis, which provided a significant discrimination (ANOSIM global test $\mathrm{R}=0.717 ; P<0.001$; PERMANOVA global test: bacteria $F=5.164, P<0.001$ ) between DGGE profiles of rumen samples considering the 3 groups: basal (before the starting of the adaptation period); rumen liquor samples collected at the end of the experiment from animals fed the L0 diet (L0) or L1.2 diet (L1.2). The results of the pairwise comparisons showed significant differences (in each case $P<0.01$ ) between the DGGE profiles of the 3 groups. If the rumen samples of the starting point of experimentations were considered separately, depending on the following L0 or L1.2 diets, ANOSIM and PERMANOVA did not

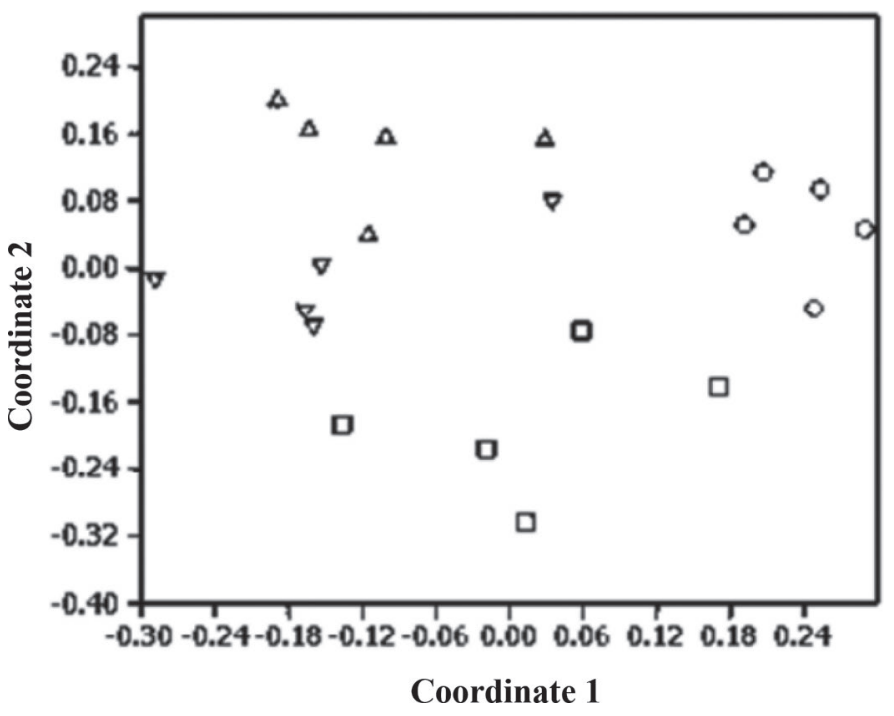

Figure 1. Nonmetric multidimensional scaling plot (2-dimensional stress $=0.2686)$ representing the distance between each rumen bacterial community in a 2-dimensional space according to $16 \mathrm{~S}$ ribosomal DNA denaturing gradient gel electrophoresis profiles. Triangles represent rumen liquor samples collected before the starting of the adaptation period from animals that during the experimental period were fed the L0 diet; inverted triangles represent rumen liquor samples collected before the starting of the adaptation period from animals that during the experimental period were fed the L1.2 diet; squares represent rumen liquor samples collected at the end of the experiment from animals fed the L0 diet; circles represent rumen liquor samples collected at the end of the experiment from animals fed the L1.2 diet. $\mathrm{L} 0=$ control diet; $\mathrm{L} 0.6=$ control diet plus $0.6 \mathrm{~g} / \mathrm{kg}$ of olive crude phenolic concentrate $(\mathrm{OCPC}) ; \mathrm{L} 0.8=$ control diet plus $0.8 \mathrm{~g} / \mathrm{kg}$ of OCPC; $\mathrm{L} 1.2=$ control diet plus $1.2 \mathrm{~g} / \mathrm{kg}$ of OCPC.

give any significant differences between DGGE profiles of these 2 groups (ANOSIM global test $\mathrm{R}=0.717 ; P<$ 0.001 ; PERMANOVA global test: bacteria $F=5.164$, $P<0.001)$.

Thus, the effects on lipid biohydrogenation observed in the present study were probably associated with changes in the overall composition of rumen microbe population. According to literature, several bacteria strains are involved in RBH. In fact, previous in vivo studies on rumen bacterial diversity in cows and ewes suggest that as-yet-uncultured bacteria phylogenetically classified as Prevotella, Lachnospinaceae, incertae sedis, and unclassified Bacteroidales, Clostridiales, and Ruminococcaceae might have a relevant role in the biohydrogenation process (Boeckaert et al., 2008; Belenguer et al., 2010; Huws et al., 2011; Castro-Carrera et al., 2014).

\section{Fatty Acid Profile of Rumen Liquor}

Increasing dose of OCPC in the diet resulted in a linear decrease $(P<0.028)$ of the $\mathrm{RBH}$ end product 
(C18:0) and of several RBH intermediates (C18:1 cis-11, C18:1 cis-12, C18:1 trans-6-8, C18:1 trans-11, C18:1 trans-15) in rumen liquor. This result, coupled with the linear increase of $\mathrm{C} 18: 2 \mathrm{n}-6, \mathrm{C} 18: 3 \mathrm{n}-3$, and C18:3 cis-9,trans-11,cis-15, clearly indicated that OCPC was able to decrease the $\mathrm{RBH}$, resulting in an accumulation of the substrates (C18:2n-6 and C18:2n $-3)$ or of the first intermediates of $\mathrm{RBH}$ (C18:3 cis9,trans-11,cis-15; Table 4). Interestingly, only a part of the RBH intermediates of $\mathrm{C} 18: 2 \mathrm{n}-6$ and $\mathrm{C} 18: 3 \mathrm{n}-3$ was affected by treatment. In particular, C18:1 cis-11, C18:1 cis- 12 , and $\mathrm{C} 18: 1$ trans-11 were considered RBH intermediates of both $\mathrm{C} 18: 2 \mathrm{n}-6$ and $\mathrm{C} 18: 3 \mathrm{n}-3$, whereas C18:1 trans-6-8 has been reported as an intermediate of RBH of $\mathrm{C} 18: 2 \mathrm{n}-6$ or, alternatively, of $\mathrm{C} 18: 1$ cis-9. Finally, C18:1 trans-15 has been associated with the RBH of C18:3n-3 (Shingfield et al., 2010). Because different RBH intermediates are associated with different metabolic pathways of the RBH of UFA (Shingfield et al., 2010), the lack of significance of the treatments on

Table 4. Fatty acid composition of rumen liquor samples at the end of the experimental period from ewes fed increasing amounts of olive crude phenolic concentrate (OCPC; data expressed as $\mathrm{mg} / \mathrm{g}$ of $\mathrm{DM})$

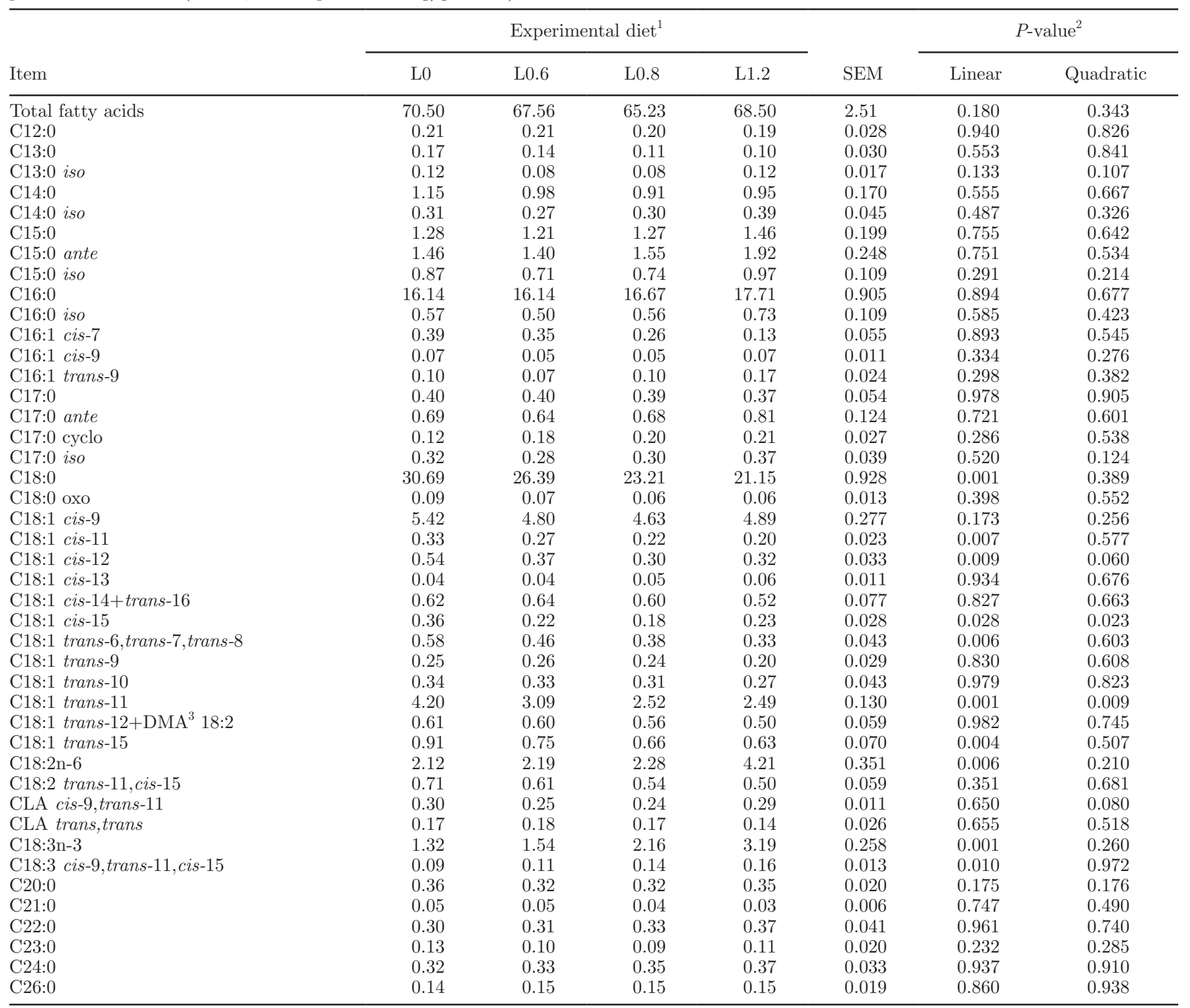

${ }^{1} \mathrm{~L} 0=$ control diet; $\mathrm{L} 0.6=$ control diet plus $0.6 \mathrm{~g} / \mathrm{kg}$ of OCPC; $\mathrm{L} 0.8=$ control diet plus $0.8 \mathrm{~g} / \mathrm{kg}$ of OCPC; L1.2 = control diet plus $1.2 \mathrm{~g} / \mathrm{kg}$ of OCPC.

${ }^{2} P$-value: significance from $P<0.05$.

${ }^{3} \mathrm{DMA}=$ dimethylacetyl. 
specific RBH intermediates could be due to a selective effect of OCPC on specific metabolic pathways.

A previous in vitro study showed that olive pomace was able to affect RBH of PUFA, leading to a decrease of C18:0 (SA) and to an increase of VA, the main intermediate of linoleic (LA) and $\alpha$-linolenic acid $(\boldsymbol{\alpha}$-LNA) RBH (Pallara et al., 2014). The authors demonstrated that these changes were related to microbiome profile modification, concluding that olive polyphenols may perturb rumen microorganisms involved in the RBH of dietary FA (Pallara et al., 2014).

The perturbation of RBH has also been demonstrated for other kind of phenolic substances such as tannins. Carreno et al. (2015), comparing different kinds and doses of tannin extracts to investigate modulation of in vitro $\mathrm{RBH}$ of FA, reported that all tannin extracts were able to modulate RBH of UFA. More recently, Costa et al. (2017) reported that condensed tannins from grape seed and, to a lesser extent, from rockrose, stimulated the first steps of RBH, with an accumulation of VA and without a clear inhibition of SA production.

Hence, data from the in vitro study from Pallara et al. (2014) suggested that olive polyphenols reduce RBH acting on the last step of the process, similarly to what was reported for tannins, whereas results of the present in vivo study suggested that the first step of RBH was probably negatively affected by olive polyphenols. This lack of consistency between in vitro and in vivo studies, and among studies in general, may be due to several factors such as the rumen passage rate, interaction with basal diet, and different amount of lipids in the diet and the specific composition of phenolic substances.

\section{Dimethylacetals in Rumen Liquor}

Alves et al. (2013), recently reported that analysis of DMA [alk-1-enyl (vinyl) ether chains] in rumen liquor may be associated with bacterial plasmalogenic lipids. Dimethylacetals derive from fatty aldehydes released from plasmalogens, which are a subclass of phospholipids contained in large amounts in membranes of anaerobic bacteria (Katz and Keeney, 1964). Although it is not yet completely demonstrated, the role of DMA might be the regulation of bacterial membrane fluidity of anaerobe bacteria in response to different environmental stimuli (Goldfine, 2010; Alves et al., 2013).

As reported in Table 5, the total amount of DMA did not vary across treatments, confirming that rumen bacteria are able to adjust the composition of membrane plasmalogenic lipids without affecting the total amount of DMA (Alves et al., 2013). Interestingly, the total amount of DMA recorded in the study of Alves et al. (2013) was lower than $0.5 \mathrm{mg} / \mathrm{g}$ of whole rumen content DM, whereas in the present trial, using the liquid rumen phase, the total amount of DMA ranged from 3.82 to $4.52 \mathrm{mg} / \mathrm{g}$ of DM for L0.8 and control diet, respectively. This large difference is probably explained by the type of rumen samples, as in the whole rumen content DM the microbial DMA concentration would be more diluted by larger amounts of undigested feed

Table 5. Total dimethylacetal (DMA; mg/g of DM) and DMA composition (\% of total DMA) of rumen liquor samples at the end of the experimental period from ewes fed increasing amounts of olive crude phenolic concentrate (OCPC)

\begin{tabular}{|c|c|c|c|c|c|c|c|}
\hline Item & \multicolumn{4}{|c|}{ Experimental $\operatorname{diet}^{1}$} & SEM & \multicolumn{2}{|c|}{$P$-value ${ }^{2}$} \\
\hline Total DMA & 4.52 & 3.94 & 3.82 & 4.15 & 0.508 & 0.47 & 0.51 \\
\hline DMAa $13: 0$ & 0.42 & 0.70 & 0.76 & 0.59 & 0.117 & 0.13 & 0.17 \\
\hline DMA 13:0 & 0.43 & 0.90 & 1.06 & 0.90 & 0.093 & 0.01 & 0.22 \\
\hline DMAi $14: 0$ & 6.28 & 6.27 & 6.46 & 6.88 & 0.392 & 0.88 & 0.68 \\
\hline DMA 15:0 & 5.45 & 6.09 & 6.20 & 5.76 & 0.159 & 0.02 & 0.44 \\
\hline DMA $16: 0$ & 47.03 & 44.15 & 43.00 & 43.56 & 0.589 & 0.02 & 0.51 \\
\hline DMA $16: 1$ & 3.62 & 3.34 & 2.77 & 1.90 & 0.397 & 0.88 & 0.07 \\
\hline DMA 17:0 & 0.85 & 0.60 & 0.54 & 0.69 & 0.086 & 0.58 & 0.10 \\
\hline DMA $17: 1$ & 2.27 & 2.74 & 2.77 & 2.34 & 0.411 & 0.30 & 0.42 \\
\hline DMA 18:0 & 2.83 & 3.15 & 3.37 & 3.50 & 0.270 & 0.50 & 0.78 \\
\hline
\end{tabular}

${ }^{1} \mathrm{~L} 0=$ control diet; $\mathrm{L} 0.6=$ control diet plus $0.6 \mathrm{~g} / \mathrm{kg}$ of OCPC; L0.8 = control diet plus $0.8 \mathrm{~g} / \mathrm{kg}$ of OCPC; L1.2= control diet plus $1.2 \mathrm{~g} / \mathrm{kg}$ of OCPC.

${ }^{2} P$-value: significance from $P<0.05$. 
than in liquid phase rumen DM. Moreover, the rumen microbiome composition or the type of animal considered could also explain the differences in DMA content between studies. The study of Alves et al. (2013), in fact, dealt with rumen liquor from lambs fed concentrate or pelleted lucerne supplemented or not with soybean oil.

Seventeen different DMA were identified in rumen liquor. Linear and branched medium chain acetals accounted for more than $85 \%$ of total DMA. The remaining part was composed by DMA with 17 or more carbon atoms. Regardless the dietary treatment, DMA16:0 was the major component, confirming what was previously reported by Alves et al. (2013). Linear medium chain DMA (DMA 13:0, DMA 14:0, DMA 15:0) linearly increased as the percentage of OCPC in the diet increased. Conversely, the percentage of DMA 16:0 linearly decreased. Among long-chain DMA, DMA 18:0 and DMA 18:1 showed an opposite trend: the former increased, whereas the latter decreased with the increasing of OCPC percentage in the diet.

Changes in the DMA relative composition did not correspond to changes in FA composition with the only exception of C18:0, which showed the same trend in both FA and DMA composition. This did not agree with Alves et al. (2013) who found a perfect correspondence between the variation of DMA and FA composition in rumen liquor samples.

As previously suggested by Alves et al. (2013), a possible explanation of the effect of dietary treatments on DMA composition of rumen liquor may be a rearrangement of membrane phospholipids of rumen bacteria in response to changes in the rumen environment associated with dietary polyphenols. However, it is not possible to exclude that changes in bacterial population composition could also be associated with changes in DMA profile of rumen liquor. For instance, although DMA 16:0 is present in the cell membrane of several bacterial strains, some species, such as Streptococcus bovis, are particularly rich in DMA 16:0 (Minato et al., 1988). At the same time, high levels of DMA 13:0 and DMA 14:0 were found in the membrane of Bacteroides succinogens and Lachnospira multiparous, respectively (Minato et al., 1988). Previous studies demonstrated that subtle dietary shifts such as the substitution of one forage by another resulted in changes in the whole rumen microflora (Dehority and Orpin, 1988; Saluzzi et al., 1995).

\section{Discriminant Analysis of DMA in Rumen Liquor}

In the present study, several DMA were found. This aspect requires appropriate interpretation to select the best DMA that discriminate between diets, as a function of external stimuli that act on the microbial com- munity. Twelve DMA that did not significantly vary in the univariate analysis (Table 5) were included in a discriminant analysis to reduce the number of original variables, identifying the latent variables called canonical. Eight DMA (DMAa 13:0, DMAi 15:0, DMAa 15:0, DMA 16:1, DMA 17:0, DMA 18:1 trans-11, DMA 18:1 cis-11, and DMA 18:1 cis-12) were selected by stepwise analysis and used for canonical discriminant analysis to evaluate the discriminant ability of these variables across the treatments. The canonical analysis extracted 3 canonical variables. Only the first 2 canonicals were considered for discriminant effect because they explained more than $92 \%$ of the variability (Table 6 ). Discriminant analysis separated without error and with significant Wilks' $\lambda$ coefficient $(P<0.001)$. Canonical 1 was able to separate the experimental treatments, whereas canonical 2 was able to discriminate the L0 diet from all the diets containing OCPC (Figure 2). Longchain DMA were positively associated with the L0 diet, whereas medium-chain DMA were positively associated with diet containing OCPC. The only exception was DMAa 15:0, which was negatively associated with both canonicals. Thus, discriminant analysis added more information about the potential association between individual DMA and specific dietary treatments, suggesting a putative role of DMA as rumen biomarkers.

\section{Milk Fatty Acid Profile}

The FA composition of milk, which was rich in VA, RA, and $\alpha$-LNA due to the presence of EL (Mele et al., 2011; Casamassima et al., 2014; Buccioni et al., 2015b), was only partially modified by the inclusion of OCPC in the diets (Table 7).

Among short-chain FA, the amount of C4:0 was significantly higher $(P<0.01)$ in milk fat from ewes fed L0.8 and L1.2 diets. This FA may originate either from elongation of acetate or by direct incorporation of butyrate produced during rumen fermentation of carbohydrates (Chilliard et al., 2007). Pallara et al.

Table 6. Discriminant dimethylacetal (DMA) by a multivariate analysis and value referring to the 2 canonicals (CAN1 and CAN2) obtained

\begin{tabular}{lrr}
\hline Item & CAN1 & \multicolumn{1}{c}{ CAN2 } \\
\hline DMAa 13:0 & 0.455 & -0.444 \\
DMAi 15:0 & 0.259 & 0.122 \\
DMAa 15:0 & -0.397 & -0.384 \\
DMA 16:1 & 0.315 & 0.181 \\
DMA 17:0 & -0.098 & 0.551 \\
DMA 18:1 trans-11 & -0.216 & 0.151 \\
DMA 18:1 cis-11 & 0.017 & 0.207 \\
DMA 18:1 cis-12 & 0.468 & 0.149 \\
Variability explained (\%) & 74.591 & 17.778 \\
Cumulative variability (\%) & 74.591 & 92.369 \\
\hline
\end{tabular}




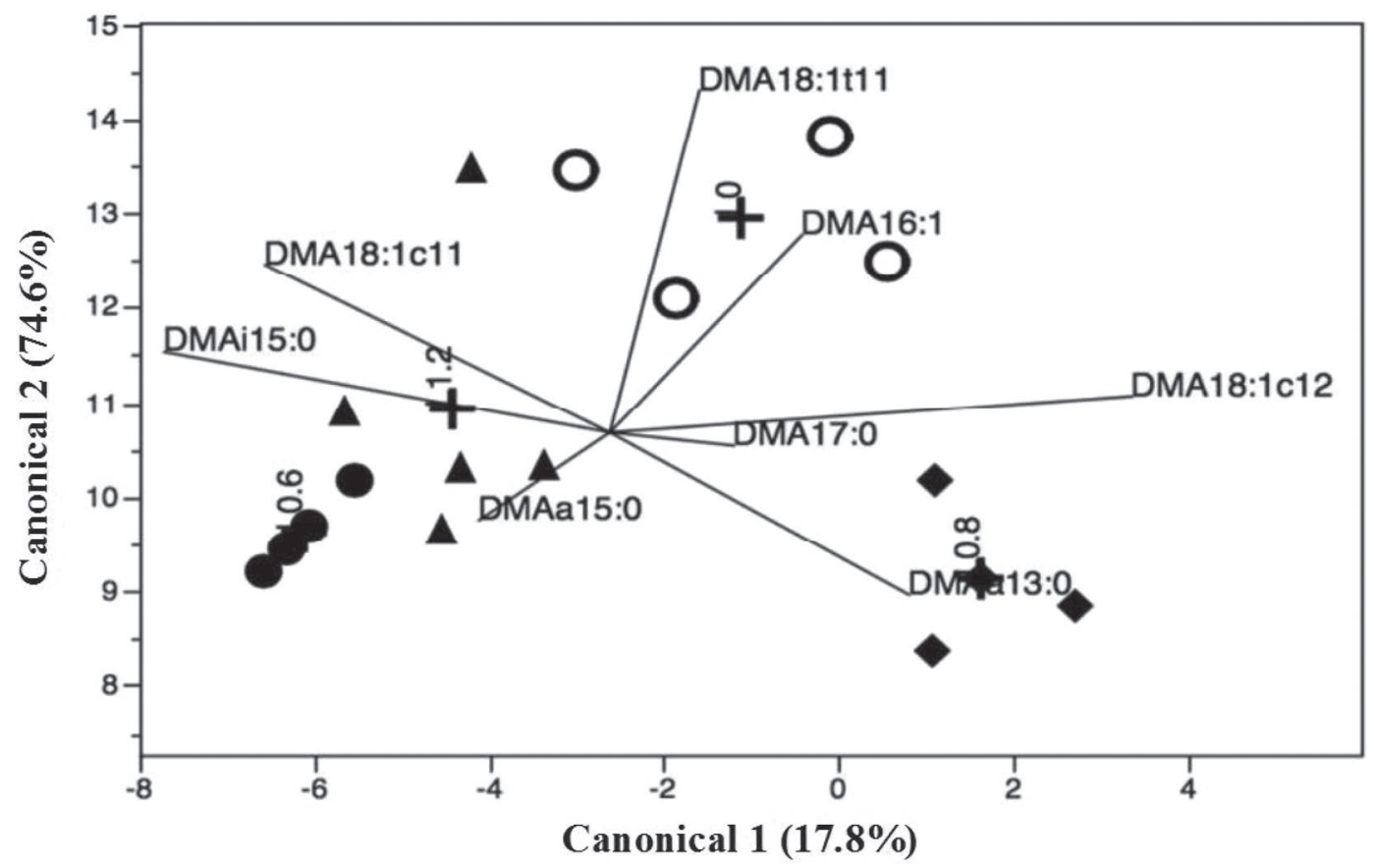

Figure 2. Plot of the dimethylacetal (DMA) and the 2 canonicals processed with a discriminant analysis. Diet profile: control (L0, empty circle); control diet plus $0.6 \mathrm{~g} / \mathrm{kg}$ of olive crude phenolic concentrate (OCPC; L0.6, full circle); control diet plus $0.8 \mathrm{~g} / \mathrm{kg}$ of OCPC (L0.8, full rhombus); control diet plus $1.2 \mathrm{~g} / \mathrm{kg}$ of OCPC (L1.2, full triangle). The plus sign represents the centroid of each group.

(2014), in a previous in vitro study, showed that supplementing olive pomace in the substrate of fermentation also stimulated the production of C4:0. Similar results were found by Yáñez Ruiz et al. (2004) feeding Granadina and Segureña goats with diets supplemented with 2-stage dried olive pomace. The authors suggested a relationship between the production of $\mathrm{C} 4: 0$ in rumen liquor and the amount of $\mathrm{C} 4: 0$ in milk.

Interestingly, although SA content in rumen liquor linearly decreased as the OCPC content in the diet increased (Table 4), the percentage of SA in milk fat did not vary across treatments. Similar results were found by Buccioni et al. (2015b) in milk from grazing ewes fed a concentrate containing EL and chestnut tannins.

Milk from the L0.8 and L1.2 group contained higher levels of LA and $\alpha$-LNA than milk from sheep fed the L0 and L0.6 diet $(P<0.001)$. Indeed, LA and $\alpha$-LNA content was significantly increased $(+18$ and $+24 \%$, respectively) when the highest level of OCPC (L1.2) was fed. This result was consistent with the higher LA and $\alpha$-LNA content found in the rumen liquor samples (Table 4). Previous studies about the effect of different kind of polyphenolic substances in the diet of dairy ruminants reported an increase of $\alpha$-LNA similar to that observed in the present study. In particular, the milk content of $\alpha$-LNA increased by almost $18 \%$ when grazing ewes were supplemented with EL and chestnut tannin extract (Buccioni et al., 2015a). Ferlay et al.
(2010), supplementing dairy cow with vitamin E, linseed, and a commercial mix of different polyphenols, reported a similar enhancement of this FA $(+23 \%)$ in milk fat.

The reduction of $\mathrm{RBH}$ intermediates, including vaccelenic acid (C18:2 trans-11,cis-15) and VA in milk from sheep fed the L0.8 and L.12 diets was a direct consequence of the lower accumulation in rumen liquor of these FA (Table 4). Lower amount of VA escaping from the rumen, moreover, led to lower production of RA in mammary gland, being the milk fat content of RA mainly due to the mammary $\Delta^{9}$-desaturation of 18:1 trans-11 (Bichi et al., 2013).

Long-chain FA, such as arachidonic acid (20:4n-6), eicosapentaenoic acid (20:5n-3), docosapentaenoic acid (22:5n-3), and docosahexaenoic acid (22:6n-3), significantly increased in milk from sheep fed L0.8 and 1.2 diets (Table 6$)(+25,+22,+33$, and $+68 \%$, respectively), probably as a consequence of the higher availability of the precursors (LA and $\alpha$-LNA, Bionaz and Loor, 2008).

\section{CONCLUSIONS}

Increasing doses of OCPC in the diet of dairy ewes supplemented with EL did not have any detrimental effect on milk yield and composition, and resulted in a linear increase of $\alpha$-LNA content in milk. Conversely, 
Table 7. Fatty acid composition of milk from sheep fed increasing amounts of olive crude phenolic concentrate (OCPC)

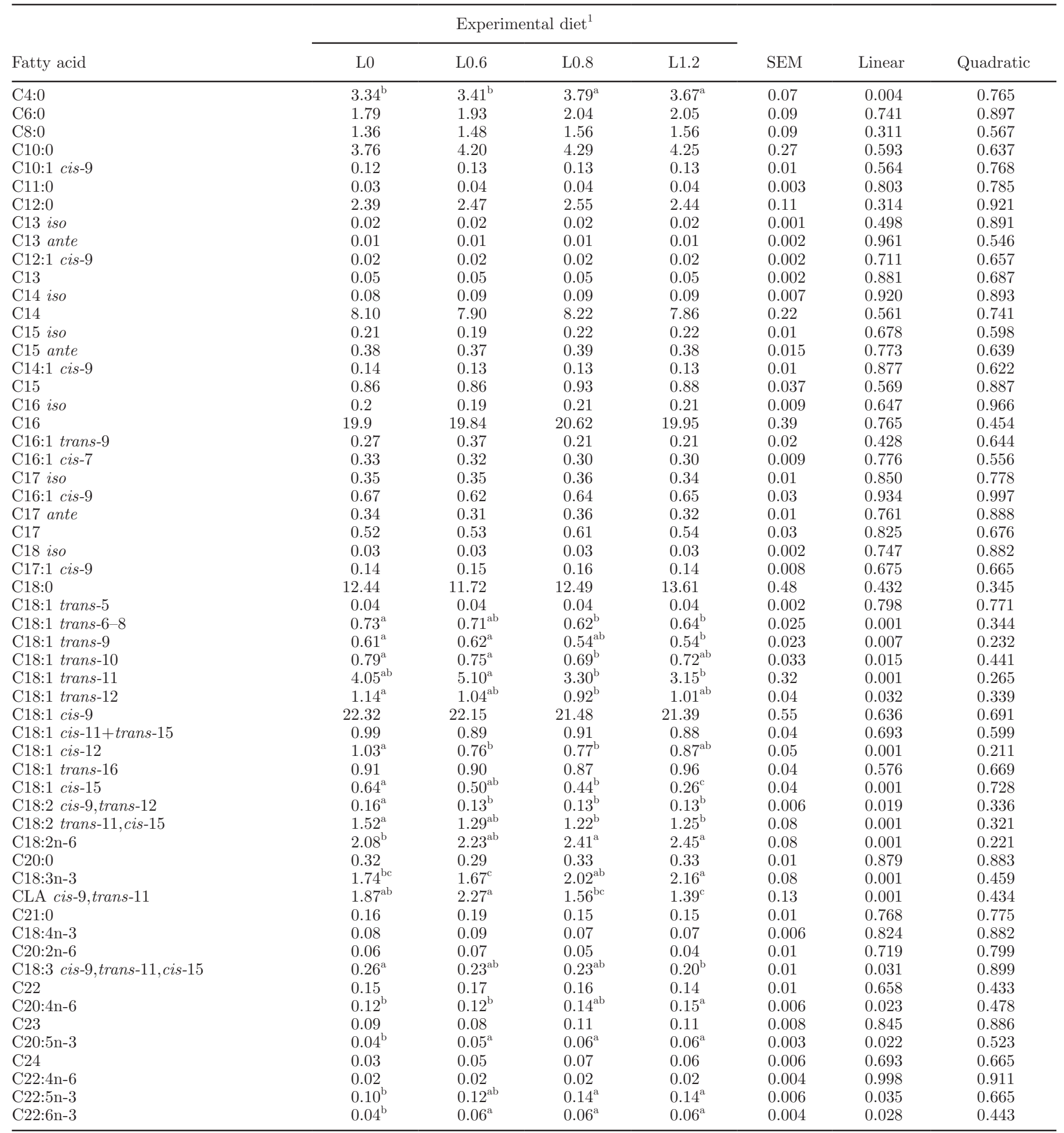

${ }^{\mathrm{a}-\mathrm{c}} P<F$ : significant differences at $P<0.05$ indicated by different superscript letters.

${ }^{1} \mathrm{~L} 0=$ control diet; $\mathrm{L} 0.6=$ control diet plus $0.6 \mathrm{~g} / \mathrm{kg}$ of OCPC; L0.8 = control diet plus $0.8 \mathrm{~g} / \mathrm{kg}$ of OCPC; L1.2= control diet plus $1.2 \mathrm{~g} / \mathrm{kg}$ of OCPC. 
the concentration of some RBH intermediates in rumen liquor and milk fat decreased with the increasing concentration OCPC in diet. This result suggested that OCPC can negatively affect the RBH of $\alpha$-LNA, allowing an accumulation of this FA in milk fat. This result may be conveniently transferred to feeding practice to reduce the amount of linseed in the diet of dairy ewes and to obtain significant enrichment of $\alpha$-LNA content in milk fat. This may lead to a decrease of feeding cost for farmers, taking into consideration that EL is an expensive dietary ingredient. However, the production of OCPC as a dietary ingredient must be improved to obtain a stable content of individual polyphenols in the OCPC. Data about DMA composition and the effects on total bacterial diversity suggested that olive polyphenols probably interfere with rumen microbiome and some DMA could be markers of this phenomenon. However, further studies are needed to find specific associations between DMA composition and individual rumen bacterial strains.

\section{ACKNOWLEDGMENTS}

The authors thanks Attilio Mazzocanti, Giovanni Migni, Giuseppe Covarelli, Osvaldo Mandoloni of "Dipartimento di Scienze Agrarie e Ambientali " University of Perugia, Italy for their technical assistance in animal management during the trial and Nuovo Molino di Assisi s.r.l. (Bastia Umbra, PG, Italy) for providing feed ingredients. This research was supported by funds from the Tuscany Region by NUTRIFOROIL Project (Italy). Moreover, part of the experimental trial was supported by funds from PRA_2017_13 (University Research Project).

\section{REFERENCES}

Alves, S. P., J. Santos-Silva, A. R. J. Cabrita, A. J. M. Fonseca, and R. J. B. Bessa. 2013. Detailed dimethylacetal and fatty acid composition of rumen content from lambs fed lucerne or concentrate supplemented with soybean oil. PLoS One 8:e58386. https://doi .org/10.1371/journal.pone.0058386.

AOAC International. 1995. Official Methods of Analysis. AOAC International, Gaithersburg, MD.

Belenguer, A., P. G. Toral, P. Frutos, and G. Hervás. 2010. Changes in the rumen bacterial community in response to sunflower oil and fish oil supplements in the diet of dairy sheep. J. Dairy Sci. 93:3275-3286.

Bichi, E., G. Hervás, P. G. Toral, J. J. Loor, and P. Frutos. 2013. Milk fat depression induced by dietary marine algae in dairy ewes: Persistency of milk fatty acid composition and animal performance responses. J. Dairy Sci. 96:524-532.

Bionaz, M., and J. J. Loor. 2008. Gene networks driving bovine milk fat synthesis during the lactation cycle. BMC Genomics 9:366-387.

Boeckaert, C., B. Vlaeminck, V. Fievez, L. Maignien, J. Dijkstra, and N. Boon. 2008. Accumulation of trans C18:1 fatty acids in the rumen after dietary algal supplementation is associated with changes in the Butyrivibrio population. Appl. Environ. Microbiol. 74:6923-6930.
Buccioni, A., M. Pauselli, C. Viti, S. Minieri, G. Pallara, V. Roscini, S. Rapaccini, M. T. Marinucci, P. Lupi, G. Conte, and M. Mele. 2015a. Milk fatty acid composition, rumen microbial population, and animal performances in response to diets rich in linoleic acid supplemented with chestnut or quebracho tannins in dairy ewes. J. Dairy Sci. 98:1145-1156. https://doi.org/10.3168/jds.2014-8651.

Buccioni, A., A. Serra, S. Minieri, F. Mannelli, A. Cappucci, D. Benvenuti, S. Rapaccini, G. Conte, and M. Mele. 2015b. Milk production, composition, and milk fatty acid profile from grazing sheep fed diets supplemented with chestnut tannin extract and extruded linseed. Small Rumin. Res. 130:200-207. https://doi.org/10.1016/ j.smallrumres.2015.07.021.

Cannas, A., L. O. Tedeschi, D. G. Fox, A. N. Pell, and P. J. Van Soest. 2004. A mechanistic model for predicting the nutrient requirements and feed biological values for sheep. J. Anim. Sci. 82:149 169. https://doi.org/10.1590/S1516-35982004000600027.

Carreno, D., G. Hervas, P. G. Toral, A. Belenguer, and P. Frutos. 2015. Ability of different types and doses of tannin extracts to modulate in vitro ruminal biohydrogenation in sheep. Anim. Feed Sci. Technol. 202:42-51. https://doi.org/10.1016/j.anifeedsci.2015 .02 .003 .

Casamassima, D., M. Nardoia, M. Palazzo, F. Vizzarri, A. G. D'Alessandro, and C. Corino. 2014. Effect of dietary extruded linseed, verbascoside and vitamin E supplements on yield and quality of milk in Lacaune ewes. J. Dairy Res. 81:485-493. https://doi .org/10.1017/S0022029914000387.

Castro-Carrera, T., P. G. Toral, P. Frutos, N. R. McEwan, G. Hervás, L. Abecia, E. Pinloche, S. E. Girdwood, and A. Belenguer. 2014. Rumen bacterial community evaluated by 454 pyrosequencing and terminal restriction fragment length polymorphism analyses in dairy sheep fed marine algae. J. Dairy Sci. 97:1661-1669.

Chilliard, Y., F. Glasser, A. Ferlay, L. Bernard, J. Rouel, and M. Doreau. 2007. Diet, rumen biohydrogenation and nutritional quality of cow and goat milk fat. Eur. J. Lipid Sci. Technol. 109:828855. https://doi.org/10.1002/ejlt.200700080.

Chiofalo, B., L. Liotta, A. Zumbo, and V. Chiofalo. 2004. Administration of olive cake for ewe feeding: Effect on milk yield and composition. Small Rumin. Res. 55:169-176. https://doi.org/10.1016/j .smallrumres.2003.12.011.

Christie, W. W. 1982. A simple procedure for rapid transmethylation of Glycerolipids and Cholesteryl Esters. J. Lipid Res. 23:10721075.

Costa, M., S. P. Alves, Â. Cabo, O. Guerreiro, G. Stilwell, M. T. Dentinho, and R. J. Bessa. 2017. Modulation of in vitro rumen biohydrogenation by Cistus ladanifer tannins compared with other tannin sources. J. Sci. Food Agric. 97:629-635. https://doi.org/10 $.1002 /$ jsfa. 7777 .

Dehority, B. S., and C. G. Orpin. 1988. Development of, and natural fluctuation in, rumen microbial populations. Pages 151-184 in The Rumen Microbial Ecosystem. P. N. Hobson, ed. Elsevier Science Publishers, London, UK.

Ferlay, A., B. Martin, S. Lerch, M. Gobert, P. Pradel, and Y. Chilliard. 2010. Effects of supplementation of maize silage diets with extruded linseed, vitamin $\mathrm{E}$ and plant extracts rich in polyphenols, and morning v. evening milking on milk fatty acid profiles in Holstein and Montbeliarde cows. Animal 4:627-640. https://doi.org/ 10.1017/S1751731109991224.

Folch, J., M. Lees, and G. H. Sloane Stanley. 1957. A simple method for the isolation and purification of total lipids from animal tissue. J. Biol. Chem. 226:497-509.

Frutos, P., G. Hervás, F. J. Giráldez, and R. Mantecón. 2004. Review. Tannins and ruminant nutrition tannins: Structure and chemical. Span. J. Agric. Res. 2:191-202. https://doi.org/10.5424/73.

Goldfine, H. 2010. The appearance, disappearance and reappearance of plasmalogens in evolution. Prog. Lipid Res. 49:493-498. https:// doi.org/10.1016/j.plipres.2010.07.003.

Hammer, R., D. A. T. Harper, and P. D. Ryan. 2001. PAST: Paleontological statistics software package for education and data analysis. Palaeontol. Electronica 4:9.

Huws, S. A., E. J. Kim, M. R. Lee, M. B. Scott, J. K. Tweed, E. Pinloche, R. J. Wallace, and N. D. Scollan. 2011. As yet uncultured 
bacteria phylogenetically classified as Prevotella, Lachnospiraceae incertae sedis and unclassified Bacteroidales, Clostridiales and Ruminococcaceae may play a predominant role in ruminal biohydrogenation. Environ. Microbiol. 13:1500-1512.

ISO-IDF. 2006. ISO13366-2/IDF148-2: Milk-Enumeration of somatic cells-Part 2: Guidance on the operation of fluoro-opto-electronic counters. International Organization for Standardization (ISO), Geneva, Switzerland; International Dairy Federation (IDF), Brussels, Belgium.

Jenkins, T. C. 2010. Technical note: Common analytical errors yielding inaccurate results during analysis of fatty acids in feed and digesta samples. J. Dairy Sci. 93:1170-1174.

Katz, I., and M. Keeney. 1964. Isolation of fatty aldehydes from rumen-microbial lipid. Biochim. Biophys. Acta 84:128-132.

Kong, Y., R. Teather, and R. Forster. 2010. Composition, spatial distribution, and diversity of the bacterial communities in the rumen of cows fed different forages. FEMS Microbiol. Ecol. 74:612-622. https://doi.org/10.1111/j.1574-6941.2010.00977.x.

Littell, R. C., P. R. Henry, and C.B. Ammerman. 1998. Statistical analysis of repeated measures data using SAS procedures. J. Anim. Sci. 76:1216-1231.

McSweeney, C. S., B. Palmer, D. M. McNeill, and D. O. Krause. 2001. Microbial interactions with tannins: Nutritional consequences for ruminants. Animal Feed Science Technol. 91:83-93. https://doi .org/10.1016/S0377-8401(01)00232-2.

Mele, M., G. Contarini, L. Cercaci, A. Serra, A. Buccioni, M. Povolo, G. Conte, A. Funaro, S. Banni, G. Lercker, and P. Secchiari. 2011. Enrichment of Pecorino cheese with conjugated linoleic acid by feeding dairy ewes with extruded linseed: Effect on fatty acid and triglycerides composition and on oxidative stability. Int. Dairy J. 21:365-372. https://doi.org/10.1016/j.idairyj.2010.12.015.

Mele, M., A. Serra, A. Buccioni, G. Conte, A. Pollicardo, P. Secchiari, D. Contenenti, D. Rapporti, and F. Concentrato. 2008. Effect of soybean oil supplementation on milk fatty acid composition from Saanen goats fed diets with different forage: concentrate ratios. Ital. J. Anim. Sci. 7:297-311.

Minato, H., S. Ishibashi, and T. Hamaoka. 1988. Cellular fatty acid and sugar composition of representative strains of rumen bacteria. J. Gen. Appl. Microbiol. 34:303-319.

Molina-Alcaide, E., E. Y. Morales-García, A. I. Martín-García, H. Ben Salem, A. Nefzaoui, and M. R. Sanz-Sampelayo. 2010. Effects of partial replacement of concentrate with feed blocks on nutrient utilization, microbial $\mathrm{N}$ flow, and milk yield and composition in goats. J. Dairy Sci. 93:2076-2087. https://doi.org/10.3168/jds .2009-2628.

Obied, H. K., P. D. Prenzler, D. Ryan, M. Servili, A. Taticchi, S. Esposto, and K. Robards. 2008. Biosynthesis and biotransformations of phenol-conjugated oleosidic secoiridoids from Olea europaea L. Nat. Prod. Rep. 25:1167-1179.
Pallara, G., A. Buccioni, R. Pastorelli, S. Minieri, M. Mele, S. Rapaccini, A. Messini, M. Pauselli, M. Servili, L. Giovannetti, and C. Viti. 2014. Effect of stoned olive pomace on rumen microbial communities and polyunsaturated fatty acids biohydrogenation: An in vitro study. BMC Vet. Res. 10:271. https://doi.org/10.1186/ s12917-014-0271-y.

Pastorelli, R., S. Landi, D. Trabelsi, R. Piccolo, A. Mengoni, M. Bazzicalupo, and M. Pagliai. 2011. Effects of soil management on structure and activity of denitrifying bacterial communities. Appl. Soil Ecol. 49:46-58.

Pintus, S., E. Murru, G. Carta, L. Cordeddu, B. Batetta, S. Accossu, D. Pistis, S. Uda, M. E. Ghiani, M. Mele, P. Secchiari, G. Almerighi, P. Pintus, and S. Banni. 2013. Sheep cheese naturally enriched in $\alpha$-linolenic, conjugated linoleic and vaccenic acids improves the lipid profile and reduces anandamide in the plasma of hypercholesterolaemic subjects. Br. J. Nutr. 109:1453-1462. https://doi.org/10.1017/S0007114512003224.

Saluzzi, L., C. S. Stewart, H. J. Flint, and A. Smith. 1995. Plasmalogens of microbial communities associated with barley straw and clover in the rumen. FEMS Microbiol. Ecol. 17:47-56.

Servili, M., M. Baldioli, R. Selvaggini, E. Miniati, A. Macchioni, and G. F. Montedoro. 1999. HPLC evaluation of phenols in olive fruit, virgin olive oil, vegetation waters and pomace and $1 \mathrm{D}$ and $2 \mathrm{D}$ NMR characterization. J. Am. Oil Chem. Soc. 76:873-882.

Servili, M., S. Esposto, G. Veneziani, S. Urbani, A. Taticchi, I. Di Maio, R. Selvaggini, B. Sordini, and G. Montedoro. 2011. Improvement of bioactive phenol content in virgin olive oil with an olivevegetation water concentrate produced by membrane treatment. Food Chem. 124:1308-1315. https://doi.org/10.1016/j.foodchem 2010.07.042.

Shingfield, K., L. Bernard, C. Leroux, and Y. Chilliard. 2010. Role of trans fatty acids in the nutritional regulation of mammary lipogenesis in ruminants. Animal 4:1140-1166. https://doi.org/10.1017/ S1751731110000510.

Shook, G. E. 1993. Genetic improvement of mastitis through selection on somatic cell count. Vet. Clin. North Am. Food Anim. Pract. 9:563-581.

Van Soest, P. J., J. B. Robertson, and B. A. Lewis. 1991. Methods for dietary fiber, neutral detergent fiber, and no starch polysaccharides in relation to animal nutrition. J. Dairy Sci. 74:3583-3597.

Vasta, V., A. Nudda, A. Cannas, M. Lanza, and A. Priolo. 2008. Alternative feed resources and their effects on the quality of meat and milk from small ruminants. Anim. Feed Sci. Technol. 147:223-246. https://doi.org/10.1016/j.anifeedsci.2007.09.020.

Yáñez Ruiz, D. R., A. I. Martín García, A. Moumen, and E. Molina Alcaide. 2004. Ruminal fermentation and degradation patterns, protozoa population and urinary purine derivatives excretion in goats and wethers fed diets based on olive leaves. J. Anim. Sci. 82:3006-3014. 